\title{
Investigation of the value of a photographic tool to measure self-perception of enamel opacities
}

Gill M Davies ${ }^{1 \dagger}$, lain A Pretty ${ }^{2 *}$, Janet S Neville ${ }^{1 \dagger}$ and Michaela Goodwin ${ }^{2 \dagger}$

\begin{abstract}
Background: The standard measurement of oral conditions that are mainly of cosmetic concern can be carried out by a trained clinical professional, or they can be assessed and reported by the individuals who may have the condition or be aware of others who have it. Enamel opacities of anterior teeth are examples of such a condition. At a public health level the interest is only about opacities that are of aesthetic concern, so the need for an index that records opacities that the public perceive to be a problem is clear. Measurement methods carried out by highly trained professionals, using unnatural conditions are not indicated at this level. This study reports on the testing of a novel epidemiological tool that aims to report on the prevalence and impact of self-perceived enamel opacities in a population of young adolescents.
\end{abstract}

Methods: A dental health survey was carried out using a random sample of 12-year-old school pupils during 2008/ 09 by Primary Care Organisations (PCOs) in England. This included the use of a novel self-perception tool which aimed to measure individual's self-perception of the presence and impact of enamel opacities to produce population measures. This tool comprised questions asking about the presence of white marks on their teeth and whether these marks bothered the volunteers and a sheet of grouped photographs of anterior teeth showing opacities ranging from TF 0, TF 1-2 to TF 2-3. Volunteers were asked which of the groups of photographs looked more like their own teeth. Examining teams from a convenience sample of 3 PCOs from this survey agreed to undertake additional measurements to assess the value of the self-perception tool. Volunteer pupils were asked the questions on a second occasion, some time after the first and clinical examiners recorded their assessments of the most closely matching set of photographs of the volunteers on two occasions.

Results: The tool was feasible to use, with $74 \%$ of pupils making a response to the first question about the presence of white marks on front teeth, $94 \%$ to the second (do these marks bother you?) and $79 \%$ to the third about which set of images most closely matched the volunteer's own, with regard to white marks. Responses to these sequential questions showed coherence with pupils who perceived themselves as having white marks on their teeth being more likely to select images that showed teeth with opacities to match with their appearance. Pupils who reported themselves concerned about their white marks were the most likely to select images with the most severe opacities. Repeatability was good among pupils (Kappa $=0.65)$ and very good among examiners (Kappa = 0.87). Agreement levels between pupil's and examiner's choice of images was poor as examiners were less likely than pupils to select images that showed more severe levels of mottling.

Conclusions: With regard to feasibility, coherence and repeatability the standardised epidemiological tool under scrutiny, with operator training, appears to be a suitable method for measuring the prevalence and impact of self-perceived enamel opacities in a population of young adolescents.

Keywords: Enamel opacities, Self-perception, Epidemiological tool

\footnotetext{
* Correspondence: iain.pretty@manchester.ac.uk

${ }^{\dagger}$ Equal contributors

${ }^{2}$ Dental Health Unit, School of Dentistry, University of Manchester, Lloyd

Street North, Manchester Science Park, England M15 6SH, UK

Full list of author information is available at the end of the article
} 


\section{Background}

Dental fluorosis has been measured using a wide range of methods, the majority of which are undertaken and reported by dental professionals [1-5]. Such methods often involve drying and illuminating teeth, photographing them and examining them at high levels of magnification against a range of clinical indices [6-8]. These techniques tend to reveal higher levels of prevalence than seen in their natural state and they include very mild levels of opacities that are potentially of little aesthetic concern at a public health or individual level. They may be relevant in clinical trials and epidemiological studies but, as they ignore the subject's voice, they are of little value in ascertaining the impact of dental fluorosis as a public health issue [9-13].

The use of clinical indices such as the DDE, TF and Dean's in epidemiological studies has been widely reported [8,14-16]. While each index has strengths and weaknesses, a common issue is the complexities in training and calibration for measurement of opacities $[8,16]$ leading to low reported agreement values between examiners, resulting in many studies being undertaken by a single examiner. The detection of mild white lines and patches on anatomical structure that are themselves white is prone to confounding issues of lighting, hydration status of the teeth, visual acuity of the examiner, angulation of viewing and the presence of plaque [17]. Such indices are based on normative standards and do not include an assessment of the subject's own view of their teeth or their appearance [18]. Therefore using measures gained solely by clinical professionals could be seen as unreliable given the difficulty to train and calibrate on a given index.

The presence of enamel opacities, including fluorosis, is only a public health problem if the public perceive it to be so. Several studies have shown that the milder levels of fluorosis are not regarded as being of aesthetic concern [18], indeed some studies have shown a preference for it compared with teeth with no opacities [19]. Therefore it is important to go to the source - the individual, to ascertain the impact of enamel opacities in an epidemiological setting.

The Water Act (2003) [20] requires that the health of persons living in the area being fluoridated should be monitored and this requirement might be expected to include the levels of fluorosis. A robust method is required whereby the levels of enamel mottling can be recorded with ease in a population and this may be done as part of the NHS Dental Epidemiology Programme in England. A method that records the perceptions of enamel opacities, and its impact upon individuals in the population would seem to be more appropriate than a measure which relates only to a normative assessment.
A simple tool was therefore developed to capture what people thought about their own teeth in an epidemiological setting. This study aimed to determine the effectiveness of using this tool to assess self reported prevalence and impact on an individual of enamel opacities in an epidemiological survey.

\section{Methods}

As part of the NHS Dental Epidemiology Programme for England all Primary Care Organisations (PCOs) were required to undertake dental health surveys of a random sample of 12-year-old school pupils during 2008 / 09 according to a national protocol. These surveys took place under the epidemiological programmes national ethical approval (Department of Health, England) and required parental opt out consent and positive consent from the participating children. The surveys took place in mainstream, state funded schools and involved sample sizes of a minimum of 250 pupils for each Local Authority and PCO. The purpose of these surveys was to measure the prevalence and severity of caries, the need and demand for orthodontic care, impact of oral disease and reported self-care. Additionally, for the first time, two questions and a photographic tool were used to collect information about self-perception of the presence and impact of enamel opacities. In this section of the survey the first question asked was "Do you have any white marks on your front teeth that won't brush off?". A second question was asked of those who replied "Yes" to the first; "Does the appearance of these marks bother you?".

In order to measure the self-perception of any enamel opacities each volunteer was then shown a sheet of grouped photographs illustrating the typical appearance of teeth that had no opacities $(\mathrm{TF}=0)$, mild opacities $(\mathrm{TF}=1-2)$ and moderate opacities $(\mathrm{TF}=2-3)$ (Figure 1). These photographs showed just the anterior teeth, with lips retracted, teeth dried, with good illumination and some minor magnification. As the photographic appearance of enamel opacities can vary with minor differences in duplication methods a standard print setting was established and the quality of each image checked against a standard image. For this reason photocopied or self printed versions of the self-perception tools were not permitted. The sets of four photographs of each fluorosis type were grouped vertically together and the groups were ordered randomly across the page. Labels for each set were chosen and used in such a way to avoid any ranking or hierarchy. All the volunteers were asked "Thinking about white marks on teeth, do you think your front teeth look more like those in this group, or the ones in this group, or this group?" while the interviewer indicated each strip of grouped photographs, in random order. 

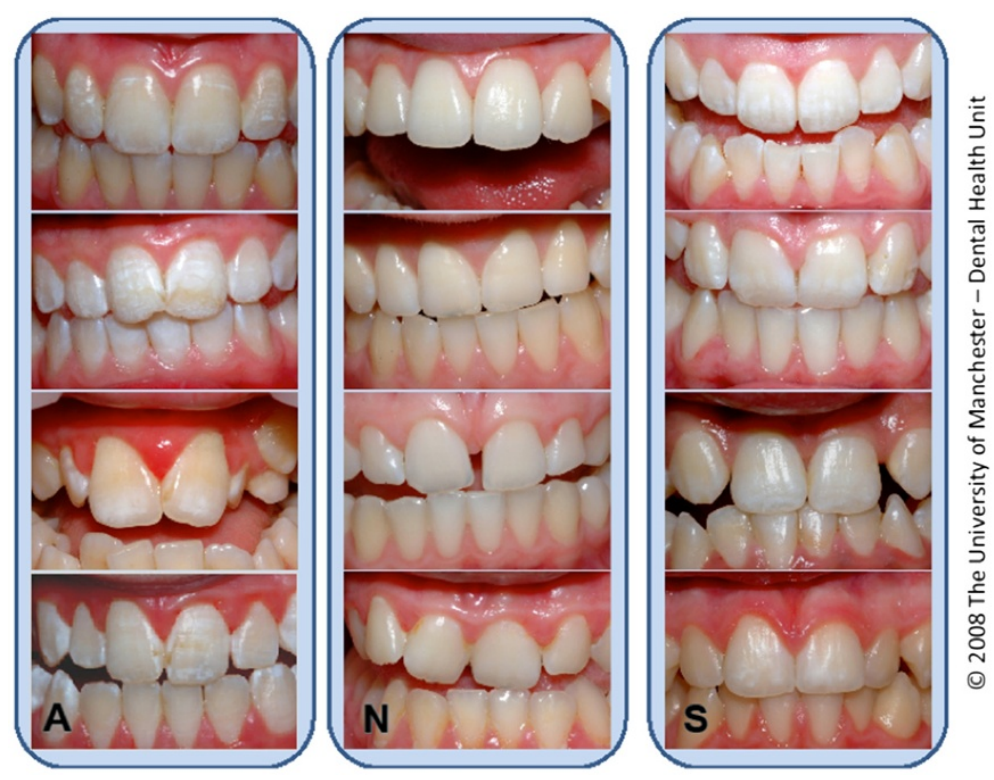

Figure 1 The self-perception tool as supplied to the examiners and volunteers. Reproduced with the permission of the copyright holders.

No mirrors were used as it was considered that those volunteers who were concerned about, or aware of, their enamel opacities would know how they looked. Those who had not noticed them previously were, de facto, not concerned about their dental appearance.

For the purpose of assessing the repeatability and use of the self-perception tool in this setting a convenience sample of three Primary Care Trusts (PCOs) agreed to carry out additional measures about enamel opacities, all in non-fluoridated areas. In two PCOs the examining dentist looked at the upper anterior teeth of each volunteer and indicated which set of photographs in the self perception tool they considered most closely matched the appearance of the volunteer with regard to enamel opacities. All three examining teams included the selfperception questions and photographic tool again when they undertook repeat examinations to test for repeatability of the enamel opacity data. To achieve this, randomly selected volunteers were asked to return at the end of an examining session so that a brief version of the overall survey could be repeated. For this second examination the sets of images on the self-perception tool were re-ordered and re-labelled so that the respondent could not simply remember which set they chose at the first time of asking. These additional data allowed for assessments of consistency and repeatability.

Data were entered into SPSS, descriptive summaries were provided for answers relating to self-perception of white marks on the teeth, for photographs selected. Analyses assessing inter-rater agreement between volunteers and examiners and intra rater agreement were conducted using the kappa statistic.

\section{Results}

The teams in three PCOs took part in additional activities to measure the effectiveness of the self-perception tool with regard to feasibility, coherence and repeatability (See Table 1). A sample of 2,803 pupil volunteers aged 12 years, were involved from the main NHS Dental Epidemiology Programme 2008/09 survey. Not all volunteer pupils were involved in all stages of the exercises as not all examiners coded the pupils against the tool (Table 2).

\section{Responses to questions}

When asked in the main survey "Do you have any white marks on your front teeth that won't brush off?" 397 out of 2,803 (14\%) volunteers responded 'yes' (Figure 2). Of

Table 1 Activities by each PCO

\begin{tabular}{llll}
\hline PCO & $\begin{array}{l}\mathbf{1}^{\text {st }} \text { examination - } \\
\text { volunteer's perception }\end{array}$ & $\begin{array}{l}\text { Repeat examination - } \\
\text { volunteer's perception }\end{array}$ & $\begin{array}{l}\mathbf{1}^{\text {st }} \text { examination - } \\
\text { examiner's perception }\end{array}$ \\
\hline Manchester & $Y(417)$ & $Y(26)$ & $N(0)$ \\
Central Lancashire/ Warrington & $Y(2386)$ & $Y(215)$ & $Y(2303)$ \\
\hline
\end{tabular}


Table 2 Selection of images showing a range of TF scores by response to questions about white marks ( $N=2800 *$ )

\begin{tabular}{|c|c|c|c|c|c|}
\hline & \multicolumn{3}{|c|}{ Set of photographs selected by volunteers } & \multirow[t]{2}{*}{ Don't know } & \multirow[t]{2}{*}{ Tota } \\
\hline & $\mathrm{TF}=0$ & $\mathrm{TF}=1-2$ & $\mathrm{TF}=2-3$ & & \\
\hline All volunteers & $1,581(56 \%)$ & $470(17 \%)$ & $256(9 \%)$ & $493(18 \%)$ & 2800 \\
\hline Those who self reported having white marks & $131(33 \%)$ & $111(28 \%)$ & $85(21 \%)$ & $70(18 \%)$ & 397 \\
\hline Those who reported no white marks & $1065(63 \%)$ & $247(15 \%)$ & $104(6 \%)$ & $271(16 \%)$ & 1687 \\
\hline Those whose self reported white marks bothered them & $21(22 \%)$ & $32(34 \%)$ & $25(27 \%)$ & $16(17 \%)$ & 94 \\
\hline Those who reported not bothered by white marks & $97(35 \%)$ & 74 (27\%) & $56(20 \%)$ & $49(18 \%)$ & 276 \\
\hline
\end{tabular}

*3 participants did not provide an answer.

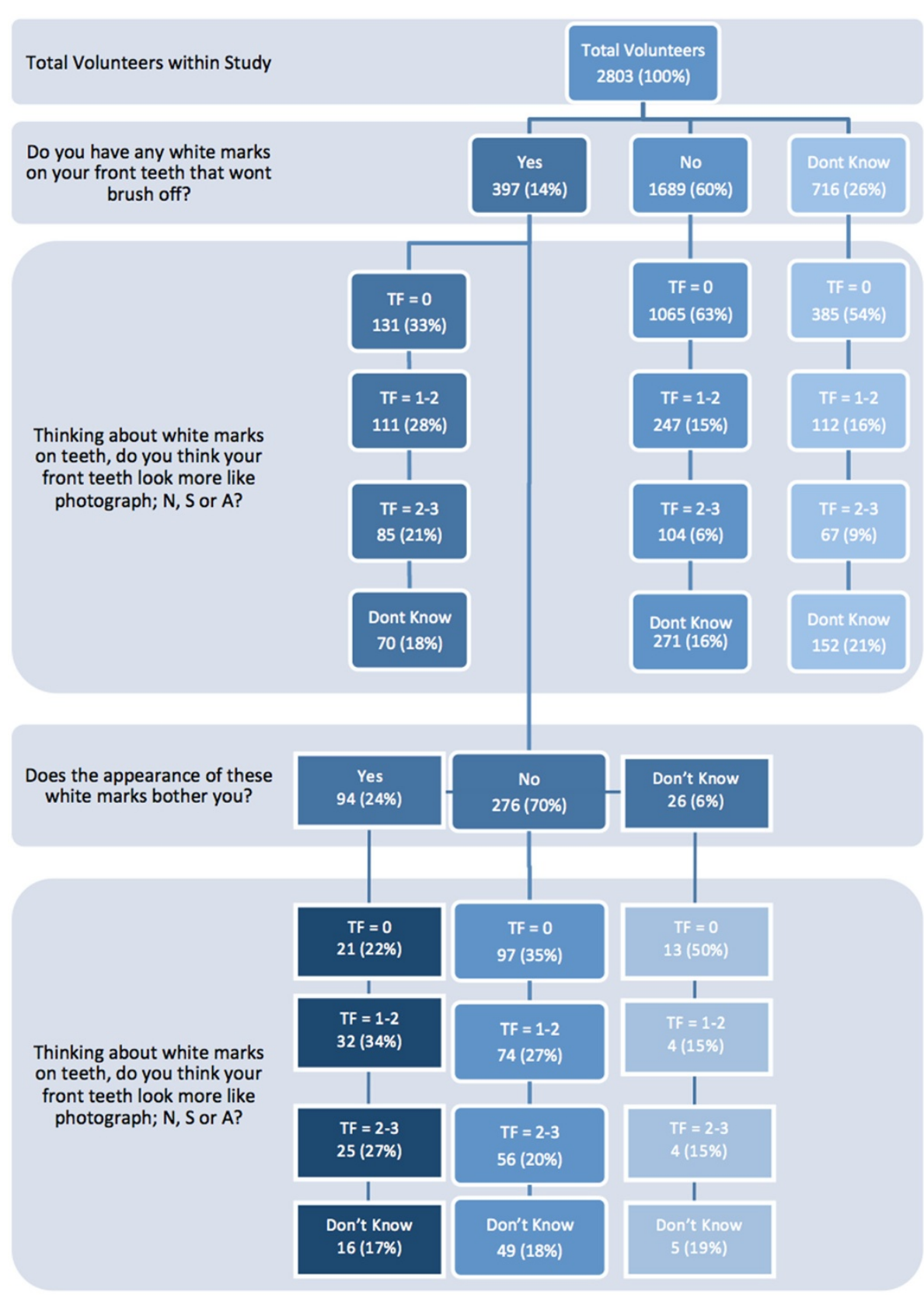

Figure 2 Flow of patient's responses. *One participant did not answer throughout questions. 
Table 3 Selection of images showing varying severity of enamel opacities by both examiners and volunteers $\left(\mathrm{N}=1913^{*}\right)$

\begin{tabular}{|c|c|c|c|c|c|c|c|c|}
\hline & \multicolumn{2}{|c|}{$\begin{array}{l}\text { Images showing } \\
\mathrm{TF}=0\end{array}$} & \multicolumn{2}{|c|}{$\begin{array}{l}\text { Images showing } \\
\text { TF } 1-2\end{array}$} & \multicolumn{2}{|c|}{$\begin{array}{l}\text { Images showing } \\
\text { TF } 2-3\end{array}$} & \multicolumn{2}{|c|}{$\begin{array}{l}\text { Response 'don't } \\
\text { know' }\end{array}$} \\
\hline & Examiner & Volunteer & Examiner & Volunteer & Examiner & Volunteer & Examiner & Volunteer \\
\hline \multirow[t]{2}{*}{ All volunteers $(n=1913)$} & 1473 & 1336 & 356 & 362 & 84 & 215 & - & 389 \\
\hline & $77 \%$ & $70 \%$ & $19 \%$ & $19 \%$ & $4 \%$ & $11 \%$ & & $17 \%$ \\
\hline \multirow{2}{*}{$\begin{array}{l}\text { Those who self reported having white marks } \\
(n=263)\end{array}$} & 114 & 108 & 106 & 85 & 43 & 70 & - & 51 \\
\hline & $43 \%$ & $41 \%$ & $40 \%$ & $32 \%$ & $16 \%$ & $27 \%$ & & $19 \%$ \\
\hline \multirow{2}{*}{$\begin{array}{l}\text { Those whose self reported white marks bothered } \\
\text { them }(n=63)\end{array}$} & 29 & 17 & 19 & 25 & 15 & 21 & - & 13 \\
\hline & $46 \%$ & $27 \%$ & $30 \%$ & $40 \%$ & $24 \%$ & $33 \%$ & & $17 \%$ \\
\hline
\end{tabular}

*sample includes cases where both the examiner and volunteer gave a response, excluding those who responded 'don't know' and 'not answered'.

these, 94 (24\% of those asked and $3.4 \%$ of the total) replied 'yes' to the follow-on question "Does the appearance of these marks bother you?".

\section{Selection of images}

When asked to indicate which set of photographs they thought most closely matched the appearance of their front teeth with regard to white marks 1,581 (56\%) indicated the set with no enamel opacities, 470 (17\%) indicated mild enamel opacities and 256 (9\%) the set with moderate opacities (Table 2). A response of 'don't know' was given by 493 (18\%) volunteers.

Among those who had self-reported having white marks there was an increased proportion who selected the images depicting more obvious opacities; $28 \%$ selecting images showing TF $1-2$ and $21 \%$ selecting TF $2-3$. This trend was seen more acutely among those who stated that their self reported white marks bothered them; $34 \%$ of these selected images of TF $1-2$ as being most like the appearance of their own teeth and $27 \%$ selecting the TF 2-3 set. Similar proportions of volunteers in these sub groups replied 'don't know' when asked to select a matching set of images. This is shown in Figure 2 which demonstrates the flow of the decisions and the selections made.

\section{Selection of images by dental examiners}

The examining dentists in two of the PCOs recorded their selection of photographs that most closely matched the appearance of 2,302 volunteers. Table 3 compares the selections made by the examiners and those made by the volunteers about themselves. The examiners considered that the images that showed no enamel opacities were the closest match for 1,473 (77\%) of the volunteers that they assessed. They considered that the photographs showing mild opacities matched with 356 (19\%) of volunteers and the images of more marked opacities matched 84 (4\%). They were more likely to select the TF $1-2$ images for those pupils who had reported that they had white marks on their teeth and more likely to select the
TF 2-3 for those reporting being bothered by their white marks, when comparing this to examiner selections for all volunteers.

The volunteers who made a selection were more likely than examiners to select the images that showed the most marked opacities (11\% vs. $4 \%$ ) and less likely than the examiners to indicate the images that showed no opacities (70\% vs. 77\%). These trends of selecting higher severity images continued amongst those who reported that they had white marks on their own teeth and were concerned by the appearance of them (33\% vs. $24 \%$ ).

When the selections of images made by the volunteers and the selections about the same volunteers made by the examiners are compared there is a poor level of agreement $($ Kappa $=0.10) \quad($ Table 4$)$. In $62 \%$ of cases there was agreement between the volunteer's and the examiner's selection of images. There was a disparity of 1 degree either way in $30 \%$ of cases, leaving $8 \%$ of cases where there was clear disagreement between the two assessments.

\section{Repeat assessments}

Repeat examinations of the pupil self-perceptions indicate that repeatability of the tool is 'good' with a Kappa value of 0.65 (Table 5). In $83 \%$ of cases the same set of images were selected on both occasions, in $14 \%$ there was a disparity of 1 level and in 3\% a disparity of two levels. Repeat examinations of the examiner classification indicate that

Table 4 Examiner assessment of enamel opacities, by self-perception of the same $(N=1913)$

\begin{tabular}{lllll}
\hline $\begin{array}{l}\text { Set of photographs } \\
\text { selected by examiner }\end{array}$ & \multicolumn{3}{c}{$\begin{array}{c}\text { Set of photographs selected } \\
\text { by volunteers }\end{array}$} & Total \\
\cline { 2 - 4 } & TF= 0 & TF = 1 - & TF = 2 - 3 & \\
\hline $\mathrm{TF}=0$ & 1,083 & 259 & 131 & 1,473 \\
$\mathrm{TF}=1-2$ & 227 & 75 & 54 & 356 \\
$\mathrm{TF}=2-3$ & 26 & 28 & 30 & 84 \\
Total & 1,336 & 362 & 215 & 1,913 \\
\hline
\end{tabular}

kappa $=0.10$, Weighted kappa $=0.14$. 
Table $\mathbf{5}$ Repeat assessment of self-perception of enamel opacities by volunteers

\begin{tabular}{|c|c|c|c|c|}
\hline \multirow{2}{*}{$\begin{array}{l}\text { Set of photographs selected by } \\
\text { volunteer at first examination }\end{array}$} & \multicolumn{3}{|c|}{ Set of photographs selected by volunteers at repeat examination } & \multirow[t]{2}{*}{ Tota } \\
\hline & $\begin{array}{l}\text { Image set } \mathrm{K} \\
\mathrm{TF}=0\end{array}$ & $\begin{array}{l}\text { Image set } \mathrm{B} \\
\mathrm{TF}=1-2\end{array}$ & $\begin{array}{l}\text { Image set } Y \\
\mathrm{TF}=2-3\end{array}$ & \\
\hline Image set $\mathrm{N}$ & 143 & 14 & 1 & 158 \\
\hline \multicolumn{5}{|l|}{$\mathrm{TF}=0$} \\
\hline Image set S & 12 & 30 & 2 & 44 \\
\hline \multicolumn{5}{|l|}{$\mathrm{TF}=1-2$} \\
\hline Image set A & 4 & 5 & 18 & 27 \\
\hline \multicolumn{5}{|l|}{$\mathrm{TF}=2-3$} \\
\hline Total & 159 & 49 & 21 & 229 \\
\hline
\end{tabular}

$(\mathrm{N}=229)$.

Kappa $=0.65=$ good agreement.

reproducibility of the tool is 'very good' with a Kappa value of 0.87 (Table 6). In $95 \%$ of cases the same set of images were selected on both occasions and in 5\% there was a disparity of 1 level.

\section{Discussion}

The purpose of this study was to assess a simple, visual tool to determine if it could measure a child's own perception of the appearance of their teeth - and in particular their own of enamel opacities. The results clearly demonstrate (see Table 2) that there is an association between the self-perception of the presence of opacities and the choice of images from the tool, in the direction one would expect. Children who consider themselves to have white marks on their teeth are more likely to select those photographs with more severe representations of mottling. The same coherence was found among the examiners' measurement using the same tool but at a lower level of severity than for the volunteers'.

Repeatability appeared to be good with regard to selection of images for pupils and very good for examiners. With only three sets of images from which to select and with very little difference between them it might have been expected that the volunteers would simply pick a set of images at random but the Kappa score of 0.65 for repeat examinations shows that this was not the case. Changing the order and the labelling of the grouped images for the second time of questioning ensured there could be no accusation of simply picking the images in the same position as the first occasion.

When considering individual responses there was poor agreement [21] between the examiner's selection of images and those of the individual volunteers. This illustrates the concerns raised about other indices of enamel opacities which are measured by trained, clinical professionals and which may over- or under-estimate the prevalence, severity and impact of enamel opacities [22]. Years of training and an underlying understanding of the biological basis for enamel opacities among examiners is in contrast to the subjective (but authentic) view of an individual based on their feelings about appearance, aesthetics and acceptability [23]. An additional point is that individual variances between examiners and pupil volunteers are unlikely to be of importance within epidemiological surveys where data are reported at group level and the purpose of such studies is to gain a view on population impact. Using responses from individual volunteers in this way is further supported when

Table 6 Repeat assessment of self-perception of enamel opacities by examiners

\begin{tabular}{|c|c|c|c|c|}
\hline \multirow{2}{*}{$\begin{array}{l}\text { Set of photographs selected by } \\
\text { examiners at first examination }\end{array}$} & \multicolumn{3}{|c|}{ Set of photographs selected by examiners at repeat examination } & \multirow[t]{2}{*}{ Total } \\
\hline & $\begin{array}{l}\text { Image set } \mathrm{K} \\
\mathrm{TF}=0\end{array}$ & $\begin{array}{l}\text { Image set B } \\
\mathrm{TF}=1-2\end{array}$ & $\begin{array}{l}\text { Image set } Y \\
T F=2-3\end{array}$ & \\
\hline Image set $\mathrm{N}$ & 183 & 3 & 0 & 186 \\
\hline \multicolumn{5}{|l|}{$\mathrm{TF}=0$} \\
\hline Image set $\mathrm{S}$ & 9 & 46 & 1 & 56 \\
\hline \multicolumn{5}{|l|}{$\mathrm{TF}=1-2$} \\
\hline Image set A & 0 & 1 & 17 & 18 \\
\hline \multicolumn{5}{|l|}{$\mathrm{TF}=2-3$} \\
\hline Total & 192 & 50 & 18 & 260 \\
\hline
\end{tabular}

$(\mathrm{N}=260)$.

Kappa $=0.87=$ Very Good agreement. 
one considers the good repeatability scores achieved by the subjects when using this tool [24].

In the national survey similar results were found to those reported here for a subset of PCOs [25]. Some variations between PCOs were found which suggest some results should be viewed with caution. For example, in one or two PCOs an unusually high proportion of pupils were reported to not know which images to select as matching with their own appearance and in other PCOs a high proportion chose not to answer one or more of the self-perception questions. This might suggest that there has been unusual administration of the tool that has lead to volunteers not engaging with the activity. This may be an issue that can be addressed through better training to ensure improved compliance with the correct method of eliciting responses.

While this study attempted to reduce the various biases that can occur in this type of survey, such as selection bias by using a random sample, order bias by scrambling the arrangement of photos to be chosen by volunteers, there are some areas that could not be lessened. For example, an issue within this type of survey is that simply asking a question about white marks may incline a participant to consider this when they never had before. Additionally, in regards to the limitations of this study, as it is purely a descriptive observational survey it cannot be used to determine the construct validity of the tool at this stage, especially given the lack of an agreed reference standard. Qualitative work would be required to gain further understanding of the different selections made and to establish if this tool really reflects how the participant feels regarding the aesthetic appearance of their teeth in relation to enamel opacities.

Tools used in epidemiological studies should be simple, efficient, and economical. They should not require complicated or expensive equipment and should be impervious, if possible, to the range of settings within which such studies are undertaken. The tool described within the current work meets these objectives and can be utilised in multiple sites simultaneously and by a number of epidemiological teams within the same site. The tool was found to be easy to implement and understood by the volunteers and requires limited training and no calibration of examiners.

\section{Conclusions}

This tool, comprising three questions and a standard set of photographs, appears to fulfill the requirements of an effective epidemiological tool with regard to feasibility, coherence and repeatability and is suitable for the measurement of self reported prevalence of enamel opacities and the impact they have in a population of young adolescents.

\section{Competing interests}

MG and IAP work within the Dental Health Unit. This Unit receives an unrestricted grant from Colgate Palmolive.

\section{Author's contributions}

GD and IAP devised the protocol and the standardised images, both contributed to writing the final manuscript. GD integrated the study into the national epidemiological programme and supported its implementation. JN entered the data and provided initial statistical support. MG undertook the analysis of the data and assisted in the preparation of the manuscript.

\section{Acknowledgements}

Thanks are given to the dental epidemiology fieldwork teams who carried out the additional investigations; Julie Laverock and Wanda Entwistle of NHS Manchester, Angela Willasey of NHS Warrington and Stephen Charnock of Central Lancashire PCT. The involvement of the schools and the pupils concerned is also gratefully acknowledged.

\section{Author details}

${ }^{1}$ The Dental Observatory, c/o Central Lancashire PCT, Jubilee House, Centurion Way, Leyland PR26 6TR, UK. ²Dental Health Unit, School of Dentistry, University of Manchester, Lloyd Street North, Manchester Science Park, England M15 6SH, UK.

Received: 3 February 2012 Accepted: 3 October 2012

Published: 9 October 2012

\section{References}

1. Angelillo IF, Torre I, Nobile CG, Villari P: Caries and fluorosis prevalence in communities with different concentrations of fluoride in the water. Caries Res 1999, 33(2):114-122.

2. Cleaton-Jones $P$, Hargreaves JA: Comparison of three fluorosis indices in a Namibian community with twice optimum fluoride in the drinking water. J Dent Assoc S Afr 1990, 45(5):173-175.

3. Pendrys DG: The differential diagnosis of fluorosis. J Publ Health Dent 1999, 59(4):235-238.

4. Pereira AC, Moreira $\mathrm{BH}$ : Analysis of three dental fluorosis indexes used in epidemiologic trials. Braz Dent J 1999, 10(1):29-37.

5. Villa $A E$, Guerrero S, Villalobos J: Estimation of optimal concentration of fluoride in drinking water under conditions prevailing in Chile. Community Dent Oral Epidemiol 1998, 26(4):249-255.

6. Ellwood R, O'Mullane D, Clarkson J, Driscoll W: A comparison of information recorded using the Thylstrup Fejerskov index, Tooth Surface Index of Fluorosis and Developmental Defects of Enamel index. Int Dent J 1994, 44(6):628-636.

7. Ellwood RP, Cortea DF, O'Mullane DM: A photographic study of developmental defects of enamel in Brazilian school children. Int Dent J 1996, 46(2):69-75.

8. Tavener J, Davies RM, Ellwood RP: Agreement amongst examiners assessing dental fluorosis from digital photographs using the TF index. Community Dent Health 2007, 24(1):21-25.

9. Sigurjons $\mathrm{H}$, Cochran JA, Ketley CE, Holbrook WP, Lennon MA, O'Mullane DM: Parental perception of fluorosis among 8-year-old children living in three communities in Iceland, Ireland and England. Community Dent Oral Epidemiol 2004, 32(Suppl 1):34-38.

10. Sujak SL, Abdul Kadir R, Dom TN: Esthetic perception and psychosocial impact of developmental enamel defects among Malaysian adolescents. J Oral Sci 2004, 46(4):221-226.

11. Vallittu PK, Vallittu AS, Lassila VP: Dental aesthetics-a survey of attitudes in different groups of patients. J Dent 1996, 24(5):335-338.

12. Williams DM, Chestnutt IG, Bennett PD, Hood K, Lowe R: Characteristics attributed to individuals with dental fluorosis. Community Dent Health 2006, 23(4):209-216.

13. Wondwossen F, Astrom AN, Bardsen A, Bjorvatn K: Perception of dental fluorosis amongst Ethiopian children and their mothers. Acta Odontol Scand 2003, 61(2):81-86.

14. Riordan PJ: Dental fluorosis, dental caries and fluoride exposure among 7-year-olds. Caries Res 1993, 27(1):71-77.

15. Sabieha AM, Rock WP: A comparison of clinical and photographic scoring using the TF and modified DDE indices. Community Dent Health 1998, 15(2):82-87 
16. Tavener JA, Davies GM, Davies RM, Ellwood RP: The prevalence and severity of fluorosis and other developmental defects of enamel in children who received free fluoride toothpaste containing either 440 or 1450 ppm F from the age of 12 months. Community Dent Health 2004 21(3):217-223.

17. Vieira AP, Lawrence HP, Limeback H, Sampaio FC, Grynpas M: A visual analog scale for measuring dental fluorosis severity. J Am Dent Assoc 2005, 136(7):895-901.

18. Browne D, Whelton H, O'Mullane D, Tavener J, Flannery E: The aesthetic impact of enamel fluorosis on Irish adolescents. Community Dent Oral Epidemiol 2011, 39(2):127-136.

19. Hawley GM, Ellwood RP, Davies RM: Dental caries, fluorosis and the cosmetic implications of different TF scores in 14-year-old adolescents. Community Dent Health 1996, 13(4):189-192.

20. HM Government: Water Act. London: HMSO; 2003.

21. Landis JR KG: The measurement of obsever agreement for categorical data. Biometrics 1977, 33:159-174.

22. Alkhatib $M N$, Holt R, Bedi R: Aesthetically objectionable fluorosis in the United Kingdom. Br Dent J 2004, 197(6):325-328. discussion 321.

23. Meneghim MC, Kozlowski FC, Pereira AC, Assaf AV, Tagliaferro EP: Perception of dental fluorosis and other oral health disorders by 12-year-old Brazilian children. Int J Paediatr Dent 2007, 17(3):205-210

24. Chankanka O, Levy SM, Warren JJ, Chalmers JM: A literature review of aesthetic perceptions of dental fluorosis and relationships with psychosocial aspects/oral health-related quality of life. Community Dent Oral Epidemiol 2010, 38(2):97-109.

25. NHS Dental Epidemiology Programme Survey of 12-year-old children, 2008/ 09: Supplementary Report - Reporting measures of plaque, self-perception of enamel opacities, self-reporting of symptoms and impact on quality of life, The Dental Observatory / North West Public Health Observatory; 2011. http:// www.nwph.net/dentalhealth/.

doi:10.1186/1472-6831-12-41

Cite this article as: Davies et al:: Investigation of the value of a photographic tool to measure self-perception of enamel opacities. BMC Oral Health 2012 12:41

\section{Submit your next manuscript to BioMed Central and take full advantage of:}

- Convenient online submission

- Thorough peer review

- No space constraints or color figure charges

- Immediate publication on acceptance

- Inclusion in PubMed, CAS, Scopus and Google Scholar

- Research which is freely available for redistribution 